\title{
Phenotype variability of neural crest derived tumours in six Italian families segregating the same founder SDHD mutation Q109X
}

\author{
L Simi, R Sestini, P Ferruzzi, M S Gaglianò, F Gensini, M Mascalchi, L Guerrini, C Pratesi, P Pinzani, \\ G Nesi, T Ercolino, M Genuardi, M Mannelli
}

J Med Genet 2005;42:e52 (http://www.jmedgenet.com/cgi/content/full/42/8/e52). doi: 10.1136/jmg.2004.030353

\begin{abstract}
Background: Mutations in genes coding for the mitochondrial complex II succinate dehydrogenase (SDH) subunits cause familial neural crest derived (NCD) tumours.

Methods: Index cases from six apparently unrelated families affected by NCD tumours were analysed for mutations in the $S D H B, S D H C$, and SDHD genes.

Results: The same nonsense germline heterozygous mutation (Q109X) in exon 4 of the SDHD gene was found in each of the six families. Overall, 43 heterozygotes were identified. These were evaluated for the presence of NCD tumours through radiological examination of the neck, thorax, and abdomen, and measurement of urinary metanephrines and plasma chromogranin A. A novel missense SDHD variant, T1121, which did not segregate with the Q109X mutation and was not associated with phenotypic manifestations, was observed in one of the families. Microsatellite analysis showed a common haplotype in all individuals heterozygous for the Q109X mutation, indicating a founder effect. Overall, 18 heterozygotes were clinically affected by at least one NCD tumour. Every affected patient inherited the germline mutation from the father, confirming SDHD maternal genomic imprinting. Penetrance of the paternally inherited mutation progressively increased from $33 \%$ to $83 \%$ at 30 and 60 years, respectively. Affected patients showed high clinical variability, ranging from monolateral to bilateral glomus tumours variably associated or not with paragangliomas or phaeochromocytomas. Loss of heterozygosity was observed in tumour cells isolated by laser capture microdissection. Conclusions: This study shows that a single founder SDHD mutation is present in an area of central ltaly and that this mutation is associated with widely variable interfamilial and intrafamilial expressivity.
\end{abstract}

$\mathrm{P}$ aragangliomas (PGLs) and phaeochromocytomas (PHEOs) are neural crest derived (NCD) tumours. Several autosomal dominant inherited syndromes predispose to PGL and/or PHEO, including von Hippel-Lindau syndrome, ${ }^{1}$ multiple endocrine neoplasia type $2,{ }^{2}$ type 1 neurofibromatosis, ${ }^{3}$ and the recently described PG/PHEO syndrome linked to mutations of genes encoding for the subunits $\mathrm{B}^{4}{ }^{4} \mathrm{C}^{5}$ and $\mathrm{D}^{6}$ of the mitochondrial complex II (succinate : ubiquinone oxidoreductase or succinate dehydrogenase; SDH).

Mitochondrial complex II consists of four subunits, each encoded by nuclear genes. Two subunits, SDHA and SDHB, constitute the hydrophilic catalytic components of the complex, while SDHC and SDHD are hydrophobic integral membrane proteins linking the catalytic subunits to the matrix side of the mitochondrial inner membrane. ${ }^{7}$ Complex II is involved in the Krebs cycle, catalysing the oxidation of succinate to fumarate, and in the aerobic electron transport chain. ${ }^{8}$ Mutations of the SDHA gene cause Leigh syndrome, the clinical features of which include optic atrophy, ophtalmoplegia, nystagmus, respiratory abnormalities, ataxia, hypotonia, spasticity, and developmental delay. ${ }^{9}$ Germline mutations of SDHD, SDHC, and SDHB cause hereditary paraganglioma syndromes (HPGLS). The three subtypes of HPGLS linked to these genes are known as PGL1, PGL-3, and PGL-4. A fourth locus has been mapped by linkage analysis but the causative gene has yet to be identified. ${ }^{10}$

PGLs can arise either from the paraganglionic bodies in the head and neck, or in the thorax or abdomen. The former are parasympathetic in origin while the latter arise from components of the sympathetic system and are usually catecholamine secreting. NCD tumours are termed PHEOs when they originate from the adrenal glands.

Recent studies seem to suggest that multiple benign head and neck PGLs may be more common in PGL-1, ${ }^{11-13}$ while SDHB mutations (PGL-4) appear to be associated with PHEOs that may be malignant ${ }^{14} 15$ and possibly also with malignancies of extraparaganglial tissues. ${ }^{16}$ In studies investigating the frequency of $S D H$ gene mutations in head and neck PGLs, $S D H D$ is reported to be the most commonly mutated gene. ${ }^{11}$ Further data are needed to define the phenotype of PGL-3, as germline mutations of SDHC (PGL-3) have only been described in four families with PGLs. ${ }^{517}$

To date, at least 37 distinct SDHD mutations have been described. ${ }^{12}{ }^{16}{ }^{18-23}$ In the course of clinical and molecular characterisation of a series of apparently unrelated Italian patients with HPGLS, we identified a recurrent SDHD mutation. We present evidence that this mutation has arisen from a common ancestral chromosome. This finding provided us with the opportunity to investigate in detail the phenotypic characteristics associated with this specific molecular alteration.

\section{METHODS}

\section{Patients and samples}

Patients gave written informed consent to the study, which had been approved by the local ethics committee of our university hospital.

Index cases were part of a large series of patients affected by NCD tumours, who were thought to be affected by a germline mutation on the basis of familial history and/or the presence of multiple tumours.

Abbreviations: HPGLS, hereditary paraganglioma syndromes; $\mathrm{LOH}$, loss of heterozygosity; NCD, neural crest derived; PGL, paraganglioma; PHEO, phaeochromocytoma; SDH, succinate dehydrogenase 
Family history was carefully reconstructed and personal clinical history was recorded for each individual. All family members participating in the study had extensive clinical evaluation and blood samples were taken for DNA analysis. Radiological examinations (mostly MRI or CT scanning, sometimes sonography) of the neck, thorax, and abdomen, and measurements of plasma chromogranin A and urinary metanephrines were performed in all participating subjects. Some patients with positive laboratory and/or radiological findings also underwent I-131-MIBG scintigraphy.

Control samples for evaluation of SDHD mutation frequencies were obtained after provision of informed consent from 100 unrelated healthy subjects from the same geographical area who did not have a history of NCD tumours.

\section{Analysis of constitutional DNA}

Genomic DNA was extracted from whole blood of 83 individuals from the six families under study, using the commercial kit NucleoSpin Blood L (Macherey-Nagel, Düren, Germany) following the manufacturer's instructions.

Direct sequencing of all $S D H B, S D H C$, and $S D H D$ exons and the exon/intron boundaries were performed in the index cases from the six families, using the primers reported in table 1 . DNA sequencing analysis was limited to the mutation bearing exon in the proband's relatives.

For PCR, $200 \mathrm{ng}$ of total DNA were amplified in a final volume of $25 \mu \mathrm{l}$. Samples were denatured for 9 minutes at $94^{\circ} \mathrm{C}$, followed by 35 cycles of amplification at $94^{\circ} \mathrm{C}$ for 1 minute, $60^{\circ} \mathrm{C}$ for 1 minute, and $72^{\circ} \mathrm{C}$ for 90 seconds in a Gene Amp 9700 Thermal Cycler (Applied Biosystems, Milan, Italy). Total PCR products were purified with a PCR purification kit (Qiagen, Milan, Italy) and semi-quantified in a $2 \%$ agarose ethidium bromide gel using DNA molecular weight marker XIV (Roche, Indianapolis, USA). To perform the cycle sequencing reaction, $20 \mathrm{ng}$ of DNA were blended with each primer $(0.8 \mu \mathrm{mol} / \mathrm{l})$ in a Big Dye Terminator ready reaction mix (Applied Biosystems), denatured for 1 minute at $96^{\circ} \mathrm{C}$, and then submitted to 25 cycles at $96^{\circ} \mathrm{C}$ for 10 seconds, $50^{\circ} \mathrm{C}$ for 5 seconds, and $60^{\circ} \mathrm{C}$ for 4 minutes. A second purification with a DyeEx 2.0 Spin kit (Qiagen) was performed for Big Dye removal, then $5 \mu$ l of purified cycle sequencing product were analysed using an ABI PRISM 310 genetic analyser (Applied Biosystems).

Simple tandem repeat polymorphisms used for genotyping and haplotype analysis have been described previously. ${ }^{13}$ Genotypes of the patients and their parents were established for markers D11S5017, D11S5015, D11S5019, D11S5030, and D11S1347. All markers were amplified using fluorescently labelled primers under standard PCR conditions. Amplicons were then submitted to ABI Prism 310 GeneScan analysis.

\section{Laser capture microdissection}

For microdissection of frozen tissue sections we used the PALM Laser Microbeam System (PALM Microlaser Technologies AG, Bernried, Germany) which enables the contact free isolation of single cells or groups of cells. Tumoral tissues submitted to this protocol were from patient III-2; family A and patient IV-3; family C. Frozen sections were mounted onto a polyethylene membrane slide and stained with haematoxylin and eosin. The microdissected cells were catapulted into the lid of a $0.5 \mathrm{ml}$ reaction tube using the laser pressure catapulting technique of the instrument. For the DNA isolation, tubes were incubated overnight at $37^{\circ} \mathrm{C}$ with $20 \mu \mathrm{l}$ of proteinase K digestion buffer ( $20 \mathrm{mmol} / \mathrm{l}$ Tris pH 8.0, 2 mmol/l EDTA, 0.5\% Igepal CA-630 (Sigma) and $20 \mu \mathrm{g} / \mathrm{ml}$ proteinase $\mathrm{K}$ ), then inactivated at $95^{\circ} \mathrm{C}$ for 10 minutes. An aliquot of this lysate was directly used for subsequent PCR and sequencing analysis to assess loss of heterozygosity $(\mathrm{LOH})$.

\section{Statistical analysis}

Penetrance of SDHD related tumours was estimated by cumulative incidence functions, using Kaplan-Meier analysis but substituting patient age for survival time. Only index cases and relatives who had inherited the germline mutation from the father and who underwent clinical screening and radiological examinations were included for penetrance calculations.

\section{RESULTS}

\section{Constitutional SDHD mutations}

The same heterozygous mutation in SDHD exon 4 was identified in each of the six index cases (fig 1B). The mutation is a $\mathrm{C} \rightarrow \mathrm{T}$ substitution in a glutamine coding codon (CAA) that converts it to a stop codon (Q109X). The mutant allele is therefore predicted to encode for a truncated protein.

The mutation was subsequently identified in $37 / 77$ relatives from the 6 families, giving a total of 43/83 carriers, including the index cases (fig $2 \mathrm{~A}-\mathrm{F}$ ).

A novel SDHD heterozygous missense change (T112I) (fig 1C) was found in seven members of family B (fig 2B).

\begin{tabular}{|c|c|c|c|c|}
\hline Gene & Exon & Forward primer & Reverse primer & $\begin{array}{l}\text { Amplicon } \\
\text { length } \\
\text { (bp) }\end{array}$ \\
\hline \multirow[t]{8}{*}{$S D H B$} & 1 & CGCCCACCCGGGAA & GTGGCTTTCCTGACTTTTCCC & 272 \\
\hline & 2 & GTATTTCTAATTTTTTTTCCTTTTTGTGA & TCTTCTCCAATAGCTGGCTTTCA & 211 \\
\hline & 3 & GCTAATACATCCAGGTGTCTCCG & CCCAACAGGAATGAAATGCTC & 201 \\
\hline & 4 & GGACTGATTCCGGATATGGGT & AATAGCGTAACACACATAGCACTGC & 256 \\
\hline & 5 & GAGTAGTCAGTGTCCAAGAAATGGG & CTATGTCCCTGCCAAGCC & 301 \\
\hline & 6 & TCTCTCCCGTCACAAGCTCC & AAACCAGGCCCCTCAGAATG & 251 \\
\hline & 7 & GAGCTTGAGTTGAGCCAGGG & CTTCTGGCGTGTCAGCTCTG & 251 \\
\hline & 8 & CTGAGGAAGGAGTTCACCCAA & TCCCTGCGGCAAGTAAAGG & 351 \\
\hline \multirow[t]{6}{*}{$S D H C$} & 1 & AACCAGCAAACCAGCTAGGC & AACAGTTATCAGCAAAACGTGAGG & 263 \\
\hline & 2 & ATCCCTTCACCCCTAAAAATAGAGA & GCTTGCAGTGAGCCGAGATC & 251 \\
\hline & 3 & GCCTGGCTTGGTATTGCAAA & TCTGGCTCCAGAATCCTTCC & 230 \\
\hline & 4 & CTATTTCAGAATTAGTTATATTTTTGCCAA & GCTGAGTTTCAAAGGAGGCG & 251 \\
\hline & 5 & TAACTTATGAGCAGCTGTGACAAGC & ССACTCCCTTCACAGAGAAAATGT & 253 \\
\hline & 6 & GGAACTGTTAATGTCCTATTACTGAAAT & ПTCCCAGGCTGGAGATAAGAAT & 251 \\
\hline \multirow[t]{4}{*}{$S D H D$} & 1 & TGACCTTGAGCCCTCAGGAACG & TCAGGGTGGGAAGACCCCT & 191 \\
\hline & 2 & GATCATCCTAATGACTCTTTTCC & AGCAGCAGCGATGGAGAGAA & 252 \\
\hline & 3 & CTITATGAATCTGGTCCTITITTG & CAACTATATTTGGAATTGCTATAC & 338 \\
\hline & 4 & AGTGGAGTGGCAAATGGAGA & AATGGCATGACAAAGCAGAGG & 360 \\
\hline
\end{tabular}




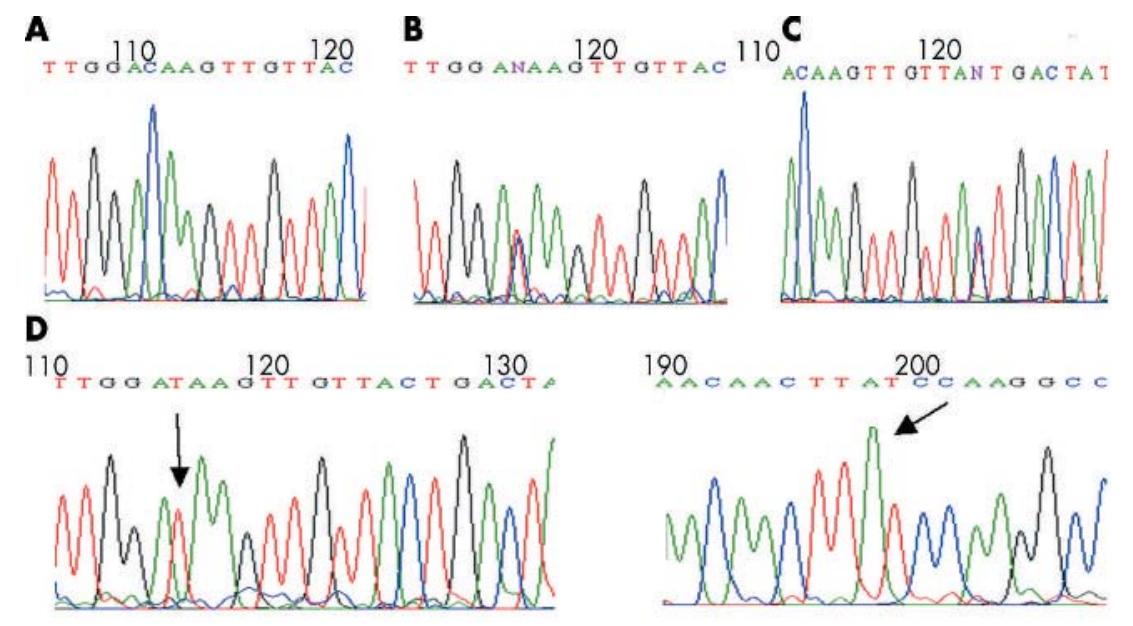

Figure 1 Electropherograms showing the exon 4 sequence of the SDHD gene: (A) wild type sequence; (B) Q109X mutation; and (C) $\mathrm{T} 112$ l substitution. In panel (D), forward and reverse sequences of tumour DNA showing $\mathrm{LOH}$ are shown. The arrows indicate the positions of the modified nucleotides.
This change was not present in any of 100 control subjects originating from the same area.

\section{Haplotype analysis}

Although no apparent relationship among the six families segregating the Q109X mutation could be found upon careful pedigree reconstruction, all families originated from a small area in the region of Tuscany. Therefore, we performed haplotype analysis to verify if the occurrence of the mutation could be due to a founder effect. Analysis of SDHD linked markers showed that a common haplotype, spanning a region of $304 \mathrm{~kb}$ that includes the SDHD gene, was present in all heterozygotes (fig 2). No recombination events were observed. In family B the T112I missense change segregated independently of the Q109X mutation (fig 2B).

\section{Loss of heterozygosity}

Sequencing analysis performed on DNA obtained from tumoral tissues was not indicative of LOH. Microdissected tumoral tissues from patient III-2, family A and patient IV-3; family $C$ showed loss of wild type allele in both the samples (fig lD).

\section{Clinical evaluation}

The clinical characteristics of Q109X mutation carriers are shown in table 2. Laboratory and radiological screening revealed the presence of one or multiple NCD tumours in 18 patients ( 8 male and 10 female patient). Each affected patient had inherited the mutation bearing chromosome from the father, while none of the carriers who inherited the mutant allele from the mother was affected by a NCD tumour.

Overall, we were able to document 48 NCD tumours. The most frequent tumour localisation was the neck, followed by the abdomen. Plasma chromogranin A levels were elevated in 10 of 14 patients harbouring a NCD tumour. Urinary metanephrines were elevated in six patients, five of whom were affected by an abdominal NCD tumour and one by a thoracic paraganglioma. Patients apparently affected only by a neck paraganglioma did not show any increase in urinary metanephrines. Multiple or recurrent NCD tumours were found in 15 of 18 patients. The mean age of clinical presentation was 39 years (range 14-69).

Radiological or laboratory evidence for the presence of NCD tumours was not found in any of the T112I heterozygotes identified in family $\mathrm{B}$.

Of the 23 patients who inherited the germline mutation from the father, three were unaffected (family B, III-6; family C, IV-20 and family F, V-6), and two (family C, II- I and
III-19), aged 76 and 52 years respectively, refused clinical evaluation. The other 18 patients had clinical and biochemical diagnosis of NCD tumours. Age related penetrance based on symptomatic and asymptomatic tumours is shown in fig 3. Penetrance values progressively increased from 33\% to $83 \%$ at 30 and 60 years respectively, and 50\% of heterozygotes were affected by 33 years of age.

\section{DISCUSSION}

$S D H D$ mutations have been shown to predispose to PGL-1. In our study, we evaluated six families affected by PGL-1 caused by the same founder mutation, Q109X. This is the first study demonstrating the existence of a PGL-1 syndrome due to a founder effect in Italy. SDHD founder mutations have been found in the Netherlands (D92Y, L139P, and L95P) ${ }^{24} 25$ and in several families in the USA (P81L), ${ }^{6}$ but not in other studies investigating families from Australia, the UK, Germany/ Poland, and Spain. ${ }^{12}$

The Q109X mutation has previously been described in only one family, the pedigree of which was characterised by the presence of two heterozygous individuals who developed carotid body tumours. ${ }^{13}$ We were able to collect clinical and genetic information from a large number of individuals belonging to the six Italian families with the Q109X mutation, which allowed us to perform genotype phenotype correlations. Haplotype analysis demonstrated that the mutation was derived from a common ancestral chromosome. Pedigree analysis showed that the PGL-1 syndrome is present only when the mutation is paternally inherited, thus confirming the maternal imprinting of the SDHD gene. ${ }^{26}$ Family E presented only one affected patient and did not contribute to the study of intrafamilial variability. Nevertheless, it constitutes a good example of maternal imprinting, as none of the affected woman's offspring, aged $44,41,33$, and 31 years, have been affected.

The most striking finding of our study is the wide variability in the clinical picture of the heterozygous individuals who had received the mutant gene from the father. Variability was observed in the age of onset, the type of clinical presentation, and number, localisation, and secreting properties of the NCD tumours. There was also intrafamilial variability in the phenotype of similar tumours. For instance, in family A, the index patient developed multiple catecholamine secreting chromaffin tumours, including bilateral PHEOs, while his sister was affected by a large ( $10 \mathrm{~cm}$ in diameter) monolateral, non-secreting PHEO at the age of 31 years.

Wide intrafamilial difference in age at presentation of glomus tumours was present, which could be partially 


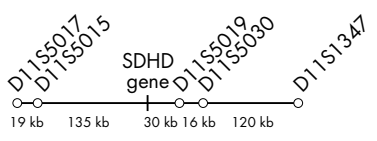

Family A

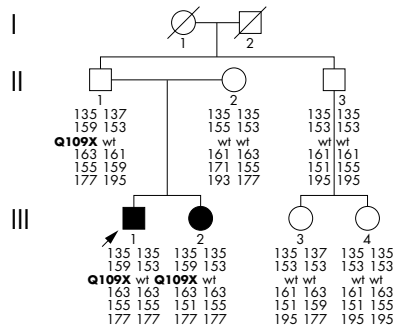

\section{Family B}

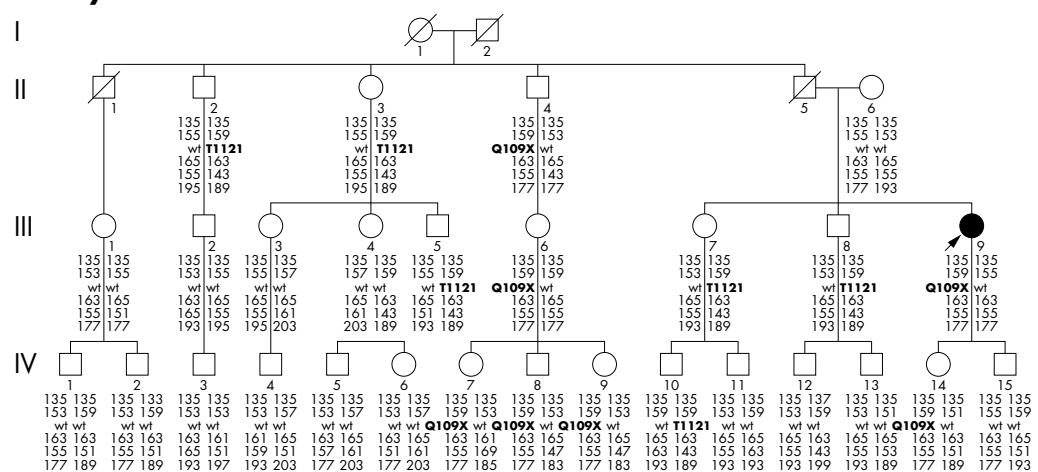

Family C

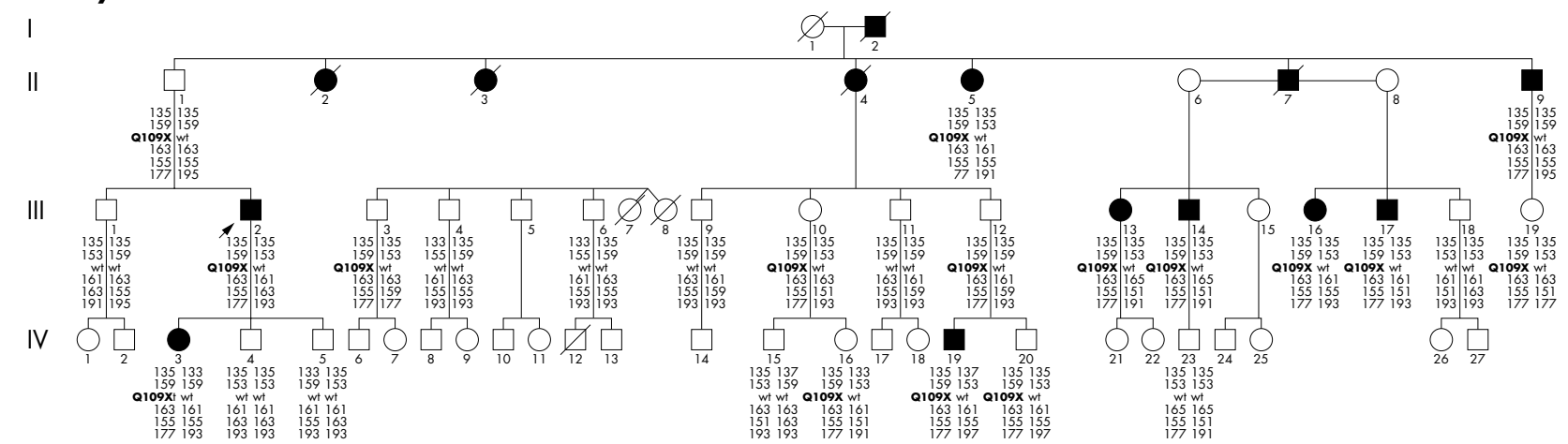

Family D

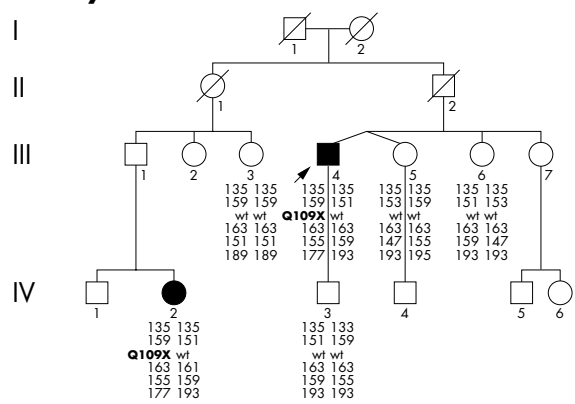

Family E

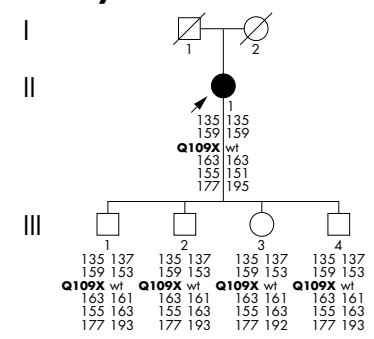

Family $F$

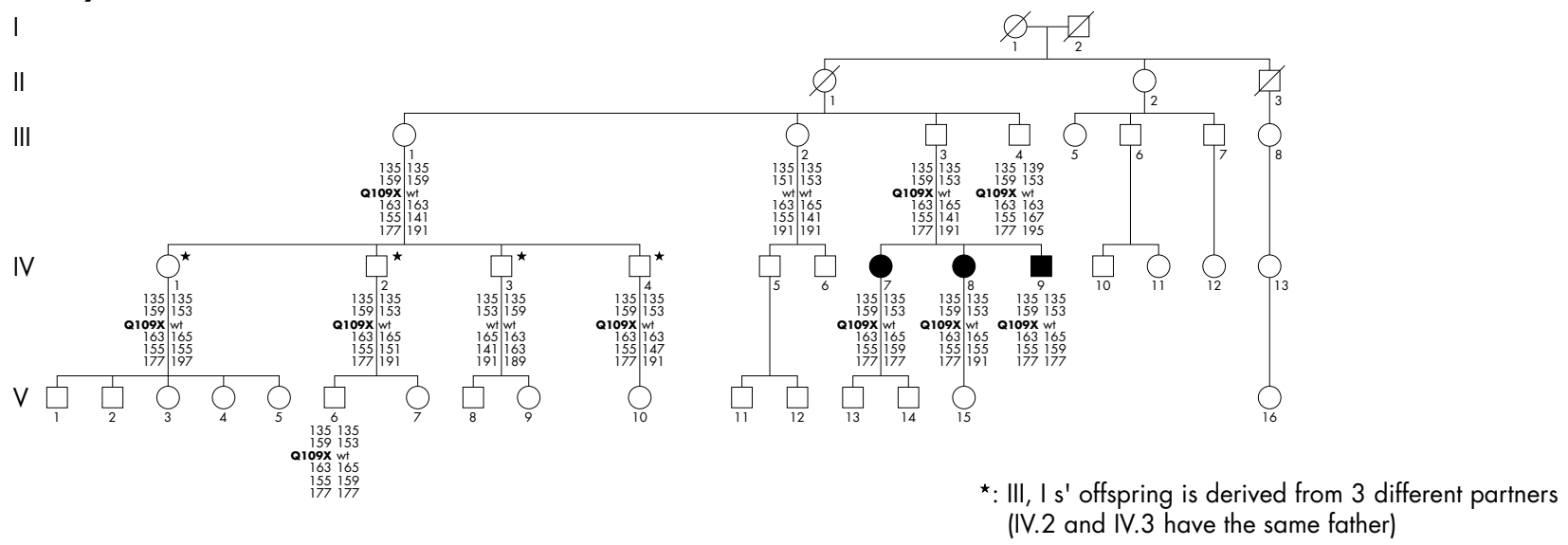

Figure 2 Pedigrees of the families segregating the Q109X mutation. Haplotypes are shown below each symbol; from top to bottom, alleles at the following loci are shown: D1 1S5017, D1 1S5015, SDHD (codon 109 or 112) D1 1S5019, D1 1S5030, and D1 1S1347. The offspring of III-I are those of three different partners (IV-2 and IV-3 have the same father). 


\begin{tabular}{|c|c|c|c|}
\hline Family & Subject & $\begin{array}{l}\text { Age at } \\
\text { onset, } \\
\text { years }\end{array}$ & Phenotype \\
\hline \multirow[t]{2}{*}{ A } & III-1 & 20 & Abdominal paragangliomas + bilateral PHEOs \\
\hline & III-2 & 31 & Right jugular paraganglioma + left PHEO \\
\hline B & IIII-9 & 43 & Bilateral carotid body paragangliomas + bladder paraganglioma \\
\hline \multirow[t]{16}{*}{ C } & $1-2$ & NK & Died at 51 years, hemiplegic, hypertensive crises (not personally evaluated) \\
\hline & $\|-1$ & NK & Not clinically evaluated \\
\hline & $\|-2$ & NK & Referred neck masses (not personally evaluated) \\
\hline & II-3 & NK & Referred neck masses (not personally evaluated) \\
\hline & II-4 & NK & Referred neck masses (not personally evaluated) \\
\hline & II-5 & 69 & Bilateral carotid body paragangliomas \\
\hline & II-7 & NK & Died at 54 years during a hypertensive crises (not personally evaluated) \\
\hline & II-9 & 66 & Bilateral carotid body paragangliomas \\
\hline & III-2 & 48 & Bilateral carotid body paragangliomas + mediastinal paraganglioma \\
\hline & III-13 & 14 & Bilateral carotid body paragangliomas + jugular paraganglioma \\
\hline & III-14 & 52 & Right glomus tumour + cerebral cavernous angiomas \\
\hline & III-16 & 31 & Right PHEO \\
\hline & III-17 & 41 & Leff glomus tumours + abdominal paraganglioma \\
\hline & III-19 & NK & Not clinically evaluated \\
\hline & IV-3 & 25 & Bilateral carotid body paragangliomas \\
\hline & IV-19 & 33 & Left glomus tumour \\
\hline \multirow[t]{2}{*}{ D } & III-4 & 57 & Left jugular-timpanic + bilateral glomus tumours \\
\hline & IV-2 & 23 & Bilateral carotid body paragangliomas \\
\hline \multirow{4}{*}{$\begin{array}{l}E \\
F\end{array}$} & $\|-1$ & 65 & Bilateral carotid body paragangliomas + paratracheal paraganglioma \\
\hline & IV-7 & 33 & Bilateral carotid body paragangliomas + bilateral vagal paragangliomas \\
\hline & IV-8 & 25 & $\begin{array}{l}\text { Laryngeal paraganglioma + right glomus tumour + right vagal-giugular } \\
\text { paraganglioma + left vagal paraganglioma }\end{array}$ \\
\hline & IV-9 & 21 & Bilateral carotid body paragangliomas \\
\hline
\end{tabular}

accounted for by tumour dimension. In family $\mathrm{C}$, age at onset ranged from 25 years in patient IV-3 to 69 years in patient II5, who was asymptomatic and diagnosed only in the course of the family screening. In this family, at least two other patients showed particular characteristics. Patient III-16 was affected by a right adrenal PHEO at the age of 31 years for which she underwent surgery; 14 years after the surgery, this seems to be the only tumour so far developed. This patient's halfbrother (III-14), in addition to having a monolateral glomus tumour, was affected by multiple cavernous cerebral angiomas (CCA). Such lesions have not been previously described in PGL-l and might represent a coincidental finding related to mutations associated with CCA.

A common feature of the NCD tumours in the families under study is the absence of malignancy, thus confirming the lack of biological aggressiveness of PGL-1 tumours. ${ }^{12}{ }^{13}$

Of 14 patients presenting a NCD tumour, four had normal chromogranin A plasma levels. Increased levels of urinary metanephrines were found only in patients with one or more documented abdominal or thoracic PGLs. Nevertheless, patient III-2 in family A and patient III-2 in family C had normal urinary metanephrines in spite of the presence of a left PHEO and a thoracic PGL, respectively. Therefore, plasma

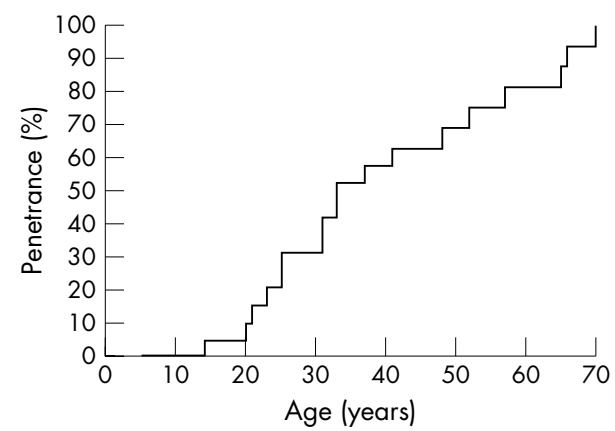

Figure 3 Age related penetrance for SDHD mutation carriers $(n=21)$. chromogranin A and urinary metanephrine assays were shown to be useful laboratory indexes for clinical assessment of these patients, although their sensitivity does not reach $100 \%$.

Of 21 patients who inherited the Q109X germline mutation from the father, 18 had a diagnosis of NCD tumours upon clinical evaluation. Three subjects were found to be unaffected by NCD tumours upon through screening; a 45 year old woman, an 18 year old man, and a 5 year old boy. Penetrance values are high, with $50 \%$ penetrance by 33 years of age, which is in agreement with data obtained through the analysis of 35 European subjects harbouring different SDHD mutations. ${ }^{16}$

Our data provide evidence of LOH in tumoral tissues, and agree with previous reports. ${ }^{27}$ Loss of maternal wild type allele was detectable only in microdissected tumoral samples that enable isolation of neoplastic chief cells exclusively, thus confirming the cellular heterogeneity of these tumors.

At present the role, if any, of the maternal allele in preventing tumour development is unknown, but $\mathrm{LOH}$ in the tumour might be one factor explaining variability of penetrance and expressivity in PGL-1. Nevertheless, it should be noted that the $S D H D$ - containing region on $11 \mathrm{q} 23$ is extremely gene rich, ${ }^{28}$ and therefore $\mathrm{LOH}$ might target a nearby gene. The extent of $\mathrm{LOH}$ might be of importance. Indeed, a recent study suggests that an exclusive loss of the entire maternal chromosome 11 is the most common second hit in SDHD linked PGLs. ${ }^{29}$ This could cause the selective loss of one or more imprinted genes in the 11 p 15 region. Further investigation of microsatellite loci and single nucleotide polymorphisms will be useful to better define the extent of the allelic loss on chromosome 11.

Different mutations affecting other loci may also be involved in tumorigenesis in the different targets of the PGL-1 syndrome. Phenotypic expression of the Q109X and other SDHD mutations could also be modulated by variants at $S D H D$ unlinked loci acting as genetic modifiers. It has been suggested that environmental factors, such as oxygen tension 
and therefore altitude, could influence penetrance and expressivity of $S D H$-linked syndromes. ${ }^{30}$ Our six families, at least for the generations we examined, have always lived in a relatively restricted area of Tuscany, in places where altitude ranges from 29 to 61 metres above sea level. Therefore, we could not document any correlation between disease expressivity and atmospheric pressure in our series. In addition, we did not observe correlations with smoking behaviour (data not shown).

In family $\mathrm{B}$, seven subjects had a novel aminoacid substitution in $S D H D, T 112 \mathrm{I}$, caused by a $\mathrm{C} \rightarrow \mathrm{T}$ transition. While this was not detected in a series of 100 control subjects living in the same area, it was found to be unassociated with phenotypic manifestations of the PGL-1 syndrome in any of the carriers. Threonine at codon 112 is conserved in Mus musculus, Rattus norvegicus, and Xenopus laevis, but not in Drosophila melanogaster, Caenorhabditis elegans, or Schizosaccharomyces pombe. Therefore, T112I is probably a rare polymorphism, although a functional effect in SDHD activity associated with low penetrance is also possible.

In conclusion, in this study we demonstrate that the PGL-1 syndrome in families originating from an area of central Italy is predominantly caused by a single founder $S D H D$ mutation. Disease transmission was confirmed to be under parent of origin effect. While penetrance of the mutation is high, its phenotypic expressivity shows wide interfamilial and intrafamilial variability. The causes of such variability and the molecular and genetic mechanisms leading to tumour formation in individuals heterozygous for such mutations will have to be further investigated.

\section{ACKNOWLEDGEMENTS}

We thank all the patients who participated in this study. We wish to thank Professors M Pazzagli and C Orlando, Department of Clinical Physiopathology, Clinical Biochemistry Unit, for advice and suggestions on laboratory technologies. We are grateful to Dr M Rotondi, Department of Clinical Physiopathology, Section of Endocrinology, for his assistance for statistical analysis. This study was conducted on behalf of ENS@T (European Network for the Study of Adrenal Tumours). This work was partly supported by grants from MIUR (Ministero dell'Istruzione, dell'Università e della Ricerca) (prot.2004069534) and Department of Clinical Pathophysiology, University of Florence. M Genuardi gratefully acknowledges the support of Ente Cassa di Risparmio di Firenze to the Fiorgen Foundation.

\section{Authors' affiliations}

P Ferruzzi, M S Gaglianò, T Ercolino, M Mannelli, Section of Endocrinology, Department of Clinical Physiopathology, University of Florence Medical School, Florence, Italy

R Sestini, F Gensini, M Genuardi, Medical Genetics, Department of Clinical Physiopathology, University of Florence Medical School, Florence, Italy

M Mascalchi, L Guerrini, Radiology, Department of Clinical Physiopathology, University of Florence Medical School, Florence, Italy C Pratesi, Section of Vascular Surgery, Department of Clinical and Surgical Critical Care, University of Florence Medical School, Florence, Italy

L Simi, P Pinzani, Clinical Biochemistry, Department of Clinical Physiopathology, University of Florence Medical School, Florence, Italy G Nesi, Department of Human Pathology and Oncology, University of Florence Medical School, Florence, Italy

M Genuardi, Fiorgen Foundation, Florence, Italy

Competing interest: there are no competing interests.

Correspondence to: Professor M Manelli, Department of Clinical Physiopathology, University of Florence, Viale Pieraccini 6, 50139 Firenze, Italy; m.mannelli@dfc.unifi.it

Received 23 December 2004

Revised 9 March 2005

Accepted 11 March 2005

\section{REFERENCES}

1 Latif F, Tory K, Gnarra J, Yao M, Duh FM, Orcutt ML, Stackhouse T, Kuzmin I, Modi W, Geil L, Schmidt L, Zhou F, Li H, Wei MH, Chen F, Glenn G, Choyke P, Walther McClellan M, Weng Y, Duan DSR, Dean M, Glava D, Richards FM, Crossey PA, Ferguson Smith MA, Le Paslier D, Chumakov I, Cohen D, Chinault AC, Maher ER, Linchan WM, Zbar B, Lerman MI. Identification of the Von Hippel-Lindau disease tumour suppressor gene. Science, 1993;260:1317-20.

2 Eng C. The RET proto-oncogene in multiple endocrine neoplasia type 2 and Hirschprung's disease. N Engl J Med 1996;335:943-51.

3 White R, O'Connell P. Identification and characterization of the gene for neurofibromatosis type 1. Curr Opin Genet Dev 1991;1:15-19.

4 Astuti D, Latif F, Dallol A, Dahia PL, Douglas F, George E, Skoldberg F, Husebye ES, Eng C, Maher ER. Gene mutations in the succinate dehydrogenase subunit SDHB cause susceptibility to familial Phaeochromocytoma and to familial paraganglioma. Am J Genet $2001 ; 69: 49-54$.

5 Niemann S, Mueller U. Mutations in SDHC cause autosomal dominant paraganglioma, type 3. Nat Genet 2000;26:268-70.

6 Baysal BE, Ferrell RE, Willett-Brozick JE, Lawrence EC, Myssiorek D, Bosch A, van der Mey A, Taschner PE, Rubinstein WS, Myers EN, Richard CW 3rd, Cornelisse CJ, Devilee P, Devlin B. Mutations in SDHD, a mitochondrial complex II gene, in hereditary paraganglioma. Science 2000;287:848-51.

7 Hagerhall C. Succinate: quinone oxidoreductases. Variations on a conserved theme. Biochim Biophys Acta 1997;1320:107-41.

8 Lancaster CRD, editor. Special issue on bioenergetics. Biochim Biophys Acta 2002;1553:1-176.

9 Shoffner JM, Wallace DC. Oxidative phosphorilation diseases. In: Scriver SC, Beaudet AL, Sly WS, Valle D, eds. The metabolic and molecular basis of inherited disease. New York: Mc-Graw-Hill, 1995:1535-1609.

10 Mariman EC, van Beersum SE, Cremers CW, Struycken PM, Ropers HH. Fine mapping of a putatively imprinted gene for familial non-chromaffin paragangliomas to chromosome 1 1 q13.1: evidence for genetic heterogeneity, Hum Genet 1995;95:56-62.

11 Badenhop RF, Jansen JC, Fagan PA, Lord RSA, Wang ZG, Foster Wi, Schofield PR. The prevalence of SDHB, SDHC and SDHD mutations in patients with head and neck paraganglioma and association of mutations with clinical features. J Med Genet 2004;41:e99.

12 Baysal BE. Hereditary paraganglioma targets diverse paraganglia. J Med Genet 2002;39:617-22.

13 Baysal BE, Willett-Brozick JE, Lawrence EC, Drovdlic CM, Savul SA, McLeod DR, Yee HA, Brackmann DE, Slattery WH 3rd, Myers EN, Ferrell RE, Rubinstein WS. Revalence of SDHB, SDHC, and SDHD germline mutations in clinic patients with head and neck paragangliomas. J Med Genet 2002;39:178-83

14 Gimenez-Roqueplo AP, Favier J, Rustin P, Rieubland C, Crespin M, Nau V Khau Van Kien P, Corvol P, Plouin PF, Jeunemaitre X. Mutations in the SDHB gene are associated with extra-adrenal and/or malignant phaeochromocytomas. Cancer Res 2003;63:5615-21.

15 Benn DE, Croxson MS, Tucker K, Bambach CP, Richardson AL, Delbridge L, Pullan PT, Hammond J, Marsh DJ, Robinson BG. Novel succinate dehydrogenase subunit $B(S D H B)$ mutations in familial phaeochromocytomas and paragangliomas, but an absence of somatic SDHB mutations in sporadic phaeochromocytomas. Oncogene 2003;22:1358-64

16 Neumann HP, Pawlu C, Peczkowska M, Bausch B, McWhinney SR, Muresan M, Buchta M, Franke G, Klisch J, Bley TA, Hoegerle S, Boedeker CC, Opocher G, Schipper J, Januszewicz A, Eng C, European-American Paraganglioma Study Group. Distinct clinical features of paraganglioma syndromes associated with SDHB and SDHD gene mutations. JAMA 2004:292:943-51.

17 Niemann S, Muller U, Engelhardt D, Lohse P. Autosomal dominant malignant and catecholamine-producing paraganglioma caused by a splice donor site mutation in SDHC. Hum Genet 2003;113:92-4.

18 Leube B, Huber R, Goecke TO, Sandmann W, Royer-Pokora B. SDHD mutation analysis in seven German patients with sporadic carotid body paraganglioma: one novel mutation, no Dutch founder mutation and further evidence that G12S is a polymorphism. Clin Genet 2004;65:61-3

19 McWhinney SR, Pilarski RT, Forrester SR, Schneider MC, Sarquis MM Dias EP, Eng C. Large germline deletions of mitochondrial complex II subunits SDHB and SDHD in hereditary paraganglioma. J Clin Endocrinol Metab 2004;89:5694-9.

20 Renard L, Godfraind C, Boon LM, Vikkula M. A novel mutation in the SDHD gene in a family with inherited paragangliomas--implications of genetic diagnosis for follow up and treatment. Head Neck 2003;25:146-51.

21 Lee SC, Chionh SB, Chong SM, Taschner PE. Hereditary paraganglioma due to the SDHD MII mutation in a second Chinese family: a founder effect? Laryngoscope 2003;113:1055-8.

22 Astuti D, Hart-Holden N, Latif F, Lalloo F, Black GC, Lim C, Moran A, Grossman AB, Hodgson SV, Freemont A, Ramsden R, Eng C, Evans DG Maher ER. Genetic analysis of mitochondrial complex II subunits SDHD, SDHB and SDHC in paraganglioma and phaeochromocytoma susceptibility. Clin Endocrinol (Oxf) 2003;59:728-33.

23 Riemann K, Sotlar K, Kupka S, Braun S, Zenner HP, Preyer S, Pfister M Pusch CM, Blin N. Chromosome 11 monosomy in conjunction with a mutated SDHD initiation codon in nonfamilial paraganglioma cases. Cancer Genet Cytogenet 2004;150:128-35.

24 Taschner PE, Jansen JC, Baysal BE, Bosch A, Rosenberg EH, BrockerVriends AH, van Der Mey AG, van Ommen GJ, Cornelisse CJ, Devilee P. Nearly all hereditary paragangliomas in the Netherlands are caused by two founder mutations in the SDHD gene. Genes Chromosomes Cancer $2001 ; 31: 274-81$ 
25 Dannenberg H, Dinjens WN, Abbou M, Van Urk H, Pauw BK, Mouwen D, Mooi WJ, de Krijger RR. Frequent germ-line succinate dehydrogenase subunit $D$ gene mutations in patients with apparently sporadic parasympathetic paraganglioma. Clin Cancer Res 2002;8:2061-6.

26 van der Mey AG, Maaswinkel-Mooy PD, Cornelisse CJ, Schmidt PH, van de Kamp JJ. Genomic imprinting in hereditary glomus tumours: evidence for new genetic theory. Lancet 1989;2:1291-4.

27 Gimenez-Roqueplo AP, Favier J, Rustin P, Mourad JJ, Plouin PF, Corvol P, Rotig A, Jeunemaitre $X$. The R22X mutation of the SDHD gene in hereditary paraganglioma abolishes the enzymatic activity of complex II in the mitochondrial respiratory chain and activates the hypoxia pathway. Am J Hum Genet $2001 ; 69: 1186-97$.
28 Baysal BE, Willett-Brozick JE, Taschner PE, Dauwerse JG, Devilee P, Devlin B. A high-resolution integrated map spanning the SDHD gene at 11q23: a 1.1 $\mathrm{Mb} \mathrm{BAC}$ contig, a partial transcript map and 15 new repeat polymorphisms in a tumour-suppressor region. Eur J Hum Genet 2001;9:121-9.

29 Hensen EF, Jordanova ES, van Minderhout IJ, Hogendoorn PC, Taschner PE, van der Mey AG, Devilee P, Cornelisse CJ. Somatic loss of maternal chromosome 11 causes parent-of-origin-dependent inheritance in SDHDlinked paraganglioma and phaeochromocytoma families. Oncogene 2004;23:4076-83.

30 Astrom K, Cohen JE, Willett-Brozick JE, Aston CE, Baysal BE. Altitude is a phenotypic modifier in hereditary paraganglioma type 1: evidence for an oxygen-sensing defect. Hum Genet 2003;113:228-37. 